\title{
Evaluation of Air Transport Benefits for the Czech Republic - Methodology Proposal
}

\section{Peter Vittek ${ }^{1}$, Sarah Van den Bergh ${ }^{1}$, Radoslav Zozulák ${ }^{1 *}$}

${ }^{1}$ Czech Technical University in Prague, Faculty of Transportation Sciences, Prague, Czech Republic

*Corresponding author: Czech Technical University in Prague, Faculty of Transportation Sciences, Horská 3, 12801 Prague,

Czech Republic, Email: zazulak@fd.cvut.cz

\begin{abstract}
The article's main purpose is to describe the proposed Methodology, which aims to present an approach to expressing the value of the air transport industry in the Czech Republic. This approach methodically divides the primary and secondary effects and finds metrics based on which the value of the air transport can be quantified. The proposed approach is based on equivalent methodological materials by ICAO, FAA, and other organizations describing and analyzing the value of air transports. The calculations are based on open data sources as well as data that are available by request. The methodology also proposes collecting new data to complete the picture of the value of air transport.
\end{abstract}

Keywords

Air transport, benefits

\section{Introduction}

Given the current development of air transport and its positive economic effects on the economy, it is relevant to carry out a periodical quantification of these effects and monitor their evolution over time. The topicality of this intent is given both by the current pandemic situation and its future development aimed at restoring the original air traffic and monitoring the performance of individual operational and manufacturing production groups that contribute to the formation of economic effects. For this purpose, we propose a methodology "Methodology for evaluating the benefits of air transport for the Czech Republic from an operational and economic point of view."
The methodology aims to describe the primary and secondary effects of air transport on the Czech Republic economy. The primary effects can be observed for airlines that carry out business activities in air transport and provide products and services. The secondary effects of air transport on the economy can be observed in companies for which air transport is an activator or a catalyst for their activities.

The primary effects capture the economic activity of companies directly from the field of aviation. Simultaneously, aviation activities producing primary effects can be further divided into direct and indirect $[1,2]$, where direct economic activities are directly related to the relocation process itself, 
mainly the activities of airlines, airports, and air traffic control. The primary effects also include the consumption of employees employed in the air transport industry. Employee consumption is defined by the term induced effect [1]. We consider indirect effects as effects of air transport on the economy created by companies' supply chain [1]. These companies provide services and products for entities with a direct impact on the economy. These are, for example, manufacturing organizations, maintenance and training organizations, or suppliers of aircraft ground handling services [1, 2, 3].

Proposed Methodology also covers secondary effects, referred to in the literature as catalytic effects, activating effects, or spillover effects $[1,2,3,4,5,6]$. Secondary effects for this Methodology's needs are described in the form of the effects of air transport on tourism and the benefits of that part of tourism activated through air transport.

Zhang and Graham [1] describe secondary effects in a broader context. Secondary effects are attributed to the effect of increasing productivity due to the densification of industrial zones and the creation of global innovations [1, 4], as well as the effect of increasing capital investment [1, 4], increasing employment [1], capital market expansion [1, 4], tourism $[1,2]$ and international trade $[1,3,4]$.

The secondary effects that act catalytically are created by the additional costs that arise from the aviation sector's activities and the wider economic benefits that air transport brings. Air transport brings benefits to the economy in the form of better access to resources [1], more accessible foreign markets $[1,6,7]$, and better availability of technology $[1,4]$. The air transport industry affects the economy and increases its efficiency [1]. At the same time, the feedback effect increases the population's purchasing power (hand in hand with the increasing economy), improving its standard of living and thus contributing to increased spending on travel and the acquisition of foreign goods transported to the country by air [1]. In general, more intense economic activities support air transport and create increased demand for air transport [1]. This feedback effect is referred to as the reciprocal causal effect [1].

In addition to tourism, air transport has a catalytic effect on productivity $[1,3,4]$, international trade $[1,3,4]$, employment in other sectors [1, 4], and foreign capital investment $[1,4,6,7,8]$. As other relevant methodologies, such as FAA methodologies $[5,9,10,11,12]$ and ATAG methodologies $[3,13,14,15,16,17]$ focus on tourism as the only catalytic effect, the focus of the proposed Methodology regarding secondary effects is also mainly on tourism.

The proposed Methodology deals with the effects of air transport acting as primary and secondary effects on the Czech Republic economy. The Methodology does not address the feedback effects as presented above.

\section{Methods}

\subsection{Methods and structure of key methodological approaches}

Currently, there are several methodological approaches of aviation organizations and institutions, which represent different perspectives on the structure, scope, methods, and means of expressing the value of air transport. When creating the Methodology for the Czech Republic, it was necessary to find the intersection of existing methodological documents ensuring international compatibility and finding differences between these documents that would capture the specifics of Czech aviation.

Oxford Economics is the leading organization that produces a range of statistical and analytical documents, economic forecasts, predictions, and estimates [18, 19, 20, 21]. Oxford Economics produces regular summary reports, for example, for IATA [22], ATAG [3, 13, 14, 15, 16, 17], and Eurocontrol [4], but also for individual countries and, to order, for commercial entities such as airports, airlines, and other companies running a business in civil aviation.

Documents published by ATAG also make an important contribution [3,13, 14, 15, 16, 17]. The ATAG membership includes 40 global companies, large international organizations, and professional associations such as the International Airports Council (ACI), the Civil Aviation Services Organization (CANSO), ICAO, and smaller professional institutions. ATAG publishes an annual evaluation report on the state of air transport, in which Oxford Economics also participates. Using the ATAG methodology [3, 13, 14, 15, 16, 17], it is possible to quantify the effects of air transport through variables such as gross domestic product (GDP), number of jobs, number of transported passengers, or revenue passenger kilometers (RPKs). It also works with the concept of direct, indirect, induced, and catalytic effects.

Within the Air Transport Industry, the ATAG methodology examines four types of businesses directly affecting the economy. These are (a) airlines, (b) airport and passenger service operators, (c) air navigation service providers, and (d) civil aeronautical manufacturers. The ATAG Methodology further defines types of business creating indirect effects. These businesses include (e) suppliers of goods and services for the above types of enterprises (a-d). Moreover, it also defines businesses having catalytic effects in the form of the development of (e) international trade, (f) tourism, (g) investments, (h) qualified labor supply, (i) market productivity, (j) socially beneficial effects, and (k) environmental effects.

As with ATAG, the FAA methodology and its results are also published at regular annual intervals [5, 9, 10, 11, 12]. The Methodology estimates the economic benefits of the Civil Aviation Industry for the United States economy. Compared to the previous ATAG approach, there is a noticeable change in the naming of the subject; it is not the Air Transport Sector, but the Civil Aviation Sector. The FAA divides the monitored structure in more detail and assesses the impacts of (a) airline operations, (b) airport operations, (c) civil aerospace production (distinguishes between aircraft and components 
manufacturing and engines manufacturing), (d) air cargo carriers, (e) tourism and tourism-related expenditure, (f) general aviation operations, manufacturing of general aviation aircraft and expenditure of general aviation tourism. The percentage share of GDP is published cumulatively and for individual components of the structure described above. In addition, the FAA publishes other economic variables, such as production, number of jobs, income, and value added. The percentage of the share of air transport in total GDP is also calculated.

There are significant overlaps and inconsistencies in details within the methodologies. There are many different perspectives on key concepts, such as direct, indirect, induced, and catalytic effects. Unifying data for air transport is an effort of ICAO, which is described in the ICAO ASA document [23], the proposal of Aviation Satellite Account.

ICAO established an Expert Advisory Group (EAG) within the Aviation Data Analysis Panel (ADAP) to prepare a methodological framework for an aeronautical satellite account based on the System of National Accounts, 2008 (SNA 2008) [24]. ICAO presented a draft of the ICAO ASA framework in September 2019 (the methodology draft is not complete yet). The methodology uses the International Standard Industrial Classification of All Economic Activities ISIC Rev. 4 [25] and the Central Product Classification version 2.1 [26]. Both classification structures were developed by the United Nations Department of Economic and Social Affairs to capture and quantify aviation and related activities, i.e., commercial air transport, general aviation, including special operations, training, airport services, and aircraft maintenance. The ICAO ASA methodology comes with a detailed classification of aviation activities, or more precisely, companies and institutions engaged in these activities, according to the Statistical Classification of Economic Activities in the European Community (NACE) [27]. The proposed Methodology is intended for the environment of the Czech Republic. Therefore, it was necessary to use the derived structure CZ-NACE [28], which is used to classify economic activities by the Czech Statistical Office [29]. Based on the statistical processing of accounting documents and statistical data, it is possible to quantify the amount of value added (VA), gross value added (GVA), or GDP by summing the relevant values for each area.

Like the FAA methodology, the ICAO ASA describes the Civil Aviation Industry.

\subsection{Methodology proposal}

The subject of the research, and one part of the Methodology, was creating a complete systematic structure of production groups to incorporate respective companies.

The methodological approach is divided into two basic directions for determining the economy's primary and secondary effects. The external structure is determined for both primary and secondary effects. The term production groups is introduced for the methodology's internal structure because described main research areas need to be further structured. Breakdown of civil aviation sector effects on the economy in terms of primary and secondary effects was first described in 2014 by FAA [12].

\subsection{External structure}

The external structure defines the primary effects from the civil aviation sector (which is further subdivided into enterprises with direct or indirect effects) supply chain point of view. Secondary effects are defined by the nature of the activities facilitated by air transport. These effects spill over from the aviation industry to other domains, such as tourism.

The methodology examines seven main segments, which according to the external structure, Methodology divides into primary effects: (1) private companies (2) state-owned enterprises, (3) airports, (4) employment, (5) air network, and secondary effects: (6) tourism and (7) air transport and its impact on GDP. This sectioning is justified by the approaches of the FAA and the work of Zhang and Graham, as described below.

According to FAA, primary effects include economic activities associated with (a) air transportation and air support services, (b) manufacturing aircraft, aircraft engines, and aircraft components, and even (c) travel and other travel expenses created by passengers transported to the country by air. The activities described in (a) and (b) are classified as direct effects, and the activities described in (c) are indirect effects. The sum of direct and indirect effects, in this case, represents the primary effects. For the Methodology purposes, primary effects constitute part (a) and (b), part (c) will be included within secondary effects (considered as part of the tourism segment).

According to FAA, the secondary effects comprise (among others) of the so-called induced effects, which are based on expenditures created by companies producing primary effects and expenditures by employees of all interested companies and institutions. Proposed Methodology marks these expenditure effects as primary, as according to Zhang and Graham [1].

Zhang and Graham [1] divide effects as (a) supply chain effects and (b) spillover/catalytic effects. Such a distinction is based on ATAG methodologies [3, 13, 14, 15, 16, 17].

Graham [1] and the ICAO ASA draft. In addition, it provides an advanced structure for catalytic effects. Therefore, the Methodology adopts the division system and the internal division of supply chain effects and catalytic effects. The proposed Methodology uses the terms primary effects (represented by supply chain effects) and secondary effects (represented by the catalytic effects). Terms primary and secondary are in accordance with the FAA methodologies $[5,9,10,11,12]$.

Induced effects consist of expenditures of employees employed within companies, which produce direct and indirect effects. There are specific differences in the methodological approaches to the effects of air transport between the FAA $[5,9,10,11,12]$ and the work of Zhang and Graham [1]. The 
latter include staff spending in the primary effects, whereas FAA considers employees expenditure as secondary effects.

The proposed Methodology focuses mainly on primary effects examining individual economic indicators within the civil aviation sector as defined by ICAO [2]. The civil aviation sector is further divided into production groups, of which complete enumeration and analysis are based on ICAO ASA structure [23].

The Methodology approaches the secondary effects mainly as those arising from tourism. The Methodology focuses on finding the context of available operational aviation data and tourism-related data within the secondary effects.

\subsection{Internal structure}

Within the internal division of Methodology, the concept of production groups is introduced. That is because the aforementioned main areas of research need to be furtherly structured. Incorporating the existing structure of the division of economic activities in the Czech Republic CZ-NACE [28] seems like an optimal thing to do. The Czech Statistical Office administers the allocation of CZ-NACE codes, and therefore it is possible to match each statistical unit with at least one CZNACE code according to the principal and collateral economic activities. These codes are determined and chosen by the respective economic entity within regular statistical surveying. The original intention to use the CZ-NACE structure is one of the logical possibilities, which is not possible due to the inaccurate classification of companies into individual sections, divisions, groups, or classes. The structure of CZ-NACE also does not reflect the actual structure of the air transport sector and its permissions and licenses.

Business and state-owned enterprises can also be found in many other CZ-NACE categories. However, these are categories in which, in addition to entities operating in civil aviation, companies from other sectors than aviation are found as well.

All companies were systematically examined according to their profiling business activities. Based on the analysis of the authorizations, certifications and licenses, the predominant activity was determined. We also assume that side activities usually support the main activity and, as a result, directly contribute to the economic results of the main activity. Aviation training as the main activity, for example, supports aircraft maintenance activity and, given that the company has the necessary equipment, it complements its business with special operations activities. Based on the searched certificates, licenses, and other permissions, economic entities were classified into nine production groups of the civil aviation sector in accordance with ICAO ASA. The production groups are and cover (1) commercial air transport services, (2) general aviation, (3) airport services, (4) air traffic control services, (5) aircraft manufacturing, (6) flight training, (7) maintenance and repairs, (8) regulators, and (9) other activities.

\subsection{Metrics of production groups}

The methodology creates a set of operational and economic metrics for individual production groups. The operational data are sourced from open data sources and data provided by the Ministry of Transport of the Czech Republic. The Czech Statistical Office provides economic data for production groups. Strict rules apply to the provision of data so that an identification of individual economic entity is not possible - aggregate data are provided for the whole production groups and their subgroups based on the list of companies' registration numbers. The following economic values are suitable for evaluating the benefits of air transport for the Czech Republic: (a) average number of employees, (b) wages, (c) total revenues, i.e., revenues from sales of products and services and sales of goods, (d) performance consumption, i.e., consumption of materials and energy, costs of services and costs spent on sold goods, and (e) value added. These values also roughly correspond to how the FAA evaluates the benefits of air transport for the United States.

The primary effects of aviation companies and other entities on the Czech Republic will be possible to describe based on the calculation of the difference between economic values (c) total revenues, i.e., sales of products and services and sales of goods, (d) production consumption, i.e., material and energy consumption and services and costs spent on sold goods. This difference expresses the economic metric gross value added (GVA). Secondary effects will be described by expressing the total consumption of tourists who arrived in the Czech Republic by air. It will be possible to express the total value of consumption as the production of tourism. These metrics will be the primary metrics expressing the impact of air traffic on the Czech Republic.

Only economic data are available to express metrics for commercial air transport services. The airlines' operational data can be found within their annual reports, but such processing is lengthy, and concerning the processed data structure, it brings inconsistent results. Therefore, the Methodology proposes a new data collection structure within the regular surveying of the Ministry of Transport of the Czech Republic. The surveying should contain a number of movements to and from individual destinations, whether directly individual destinations or aggregated data for countries and the number of passengers in both directions.

For the general aviation production group, three basic production subgroups can be observed: (a) aeroclubs, (b) special operation aircraft operators (SPOs), and (c) general aviation manufacturing. Subgroup (a) aeroclubs can only be described based on operational performance, particularly based on aviation activity determined by the number of movements at individual airports. Data on the financial results of aeroclubs cannot be processed automatically because the structure of their financial statements does not allow it. In the case of operators of special operations activities, it is possible to monitor how many economic entities there are and, in the case of correct provision of statistical data, the economic values. 
As for the manufacturers of general aviation aircraft, economic values can be monitored in sufficient data quality. The Light Aircraft Association of the Czech Republic has the best overview of operational metrics. Therefore, it would be appropriate to establish cooperation ensuring data integration of their sources. The proposed cooperation may result in other metrics such as the number of produced aircraft, the percentage of exports, etc.

Both economic and operational metrics are available for airports. Both types of metrics are based on open data sources. As for economic metrics, it is important to monitor airports classified into subgroups L1, L2, and L3 (L4 and L5 are irrelevant for the airports production group). Listed groups L1 and L2 represent the largest international and regional airports; L3 represents a group of smaller airports with lesser importance operated by private companies. Other airports groups are aeroclub-operated airports having a voluntary association legal identity. Their financial statements and thus also economic values cannot be processed for the reasons described above. It is more appropriate to monitor their operational performance within the general aviation production group, as aircraft movements correspond to the character of this production group.

The air navigation service provider (ANSP) production group is a group of several companies. The leading entity of this group is the Air Navigation Services of the Czech Republic. Financial statements of companies enlisted in this group are open-access; they are in a conventional format and allow automatic processing. Statistical surveys need to be focused on operational metrics (e.g., number of controlled flights) of this production group.

The aircraft and aircraft technology manufacturing and the airport production groups are among the most potent production groups in terms of economic benefits. Data collected and processed by the Czech Statistical Office allow monitoring of economic values for the manufacturing production group. It is also suitable to monitor operating values like the number of manufactured aircraft and aircraft components. An important indicator is also the share of exports in production.

The aviation training production group associates companies with the appropriate certifications and authorizations in general to conduct pilot and aviation maintenance technician training. The Czech Statistical Office has quality data to describe the complete structure of economic values of these enterprises. In addition, it is suitable to monitor operational values such as the number of movements during flight training, the number of students, and the number of flying hours in training.

Regulators, state supervision, and authorized organizations is another production group overseeing the implementation, execution, and compliance of relevant standards, safety standards, and the investigation of aviation incidents and accidents. Monitoring financial values is ineffective. Therefore, the Methodology will monitor the number of employees in respective entities.
The last production group gathers the remaining entities that could not fit in any previous production group. These are mainly educational organizations such as high schools, universities, wholesalers, and museums. It is in the interest of the Methodology to monitor the numbers of students in individual aviation study programs.

Herfindahl-Hirschman Index (HHI) is used to overview the air network. It is possible to monitor both the number of passengers and the number of movements in each direction. The ratio of passengers to a number of movements expresses the ratio of the number of passengers per one movement. Through this indicator ratio, it is possible to monitor density - aircraft occupancy in every direction. These data are available through the Eurostat database. However, data for the Czech Republic are limited to just countries (Czech Republic - country). For several other countries, data include individual city - city connections. Among other recommendations of the Methodology for the Czech Republic is to monitor these air connections in more detail. These data could give more clearance and guidance on the characteristics of individual air connections. We assume that the aircraft capacity of flights from/to airports with prevailing low-cost and charter operations will have higher ratio indicator, while airports with prevailing network carriers operations will have a lower ratio indicator. An overview of charter, low-cost, business and standard network carriers flights can be obtained from Eurocontrol databases.

\section{Conclusion}

There are two main metrics for expressing the value of the Civil Aviation Industry for the Czech Republic. The first is the gross value added of primary production groups. The second metric is the estimated value of spendings of tourists who arrived by air in the Czech Republic, which can be described as production. The size of production is also reported due to the annual results of the tourism satellite account.

The main economic metric of primary production groups is the gross value added. This metric can be calculated from data obtained by the Czech Statistical Office. The calculation of gross value added for expressing the value of air transport for the Czech Republic is possible by calculating the difference between the value of (c) total revenues, i.e., revenues of products, services and goods, (d) production consumption, i.e., material and energy consumption and the cost of services and sold goods. Gross value added is possible to calculate for most of the production groups defined by the Methodology.

The essential task for improving the achievability of the gross value added metric is to publish a proposal for the structure of companies and other entities active in the aviation sector within individual primary production groups. Aviation companies and other entities must be appropriately integrated within the CZ-NACE structure to allocate their production results appropriately within the CZ-NACE structure. Furthermore, it is necessary to raise awareness among aviation companies and other entities so that, within the framework 
of statistical reporting, the responsible staff correctly assigns individual parts of production results to individual groups of CZ-NACE.

As for the secondary production group, which is represented in the Methodology by tourism, it is possible to calculate the value of the expenses of tourists who arrived by air based on the sum of passengers' expenses from individual countries. These expenses are determined by the number of passengers who entered the country by air, average daily expenditure, and the average length of stay. The expenses of tourists transported by air represent the production within the tourism satellite account. Therefore, we can further monitor the share of production created by tourists transported by air on the total production of tourism.

\section{Acknowledgements}

The study was performed as part of the project funded by the Technology Agency of the Czech Republic: project No. TL01000421 - TACR Eta - "Value of Air Transport in Czech Republic".

\section{References}

[1] Fangni Zhang and Daniel J. Graham. Air transport and economic growth: a review of the impact mechanism and causal relationships. Transport $R e$ views, 40(4):506-528, March 2020. doi: 10.1080/ 01441647.2020.1738587. URL https : / / doi .org/ $10.1080 / 01441647.2020 .1738587$.

[2] Industry High Level Group (IHLG). Aviation Benefits Report. 2019. URL https://Www.icao.int/ sustainability/Documents/AVIATIONBENEFITS-2019-web.pdf.

[3] Air Transport Action Group. Aviation: Benefits Beyond Borders. 2020. URL https: //www. atag.org/component/attachments / attachments.html?id=954.

[4] A. Cooper and P. Smith. The economic catalytic effects of air transport in Europe. EUROCONTROL Experimental Centre, 2005.

[5] Federal Aviation Administration. The Economic Impact of Civil Aviation on the U.S. Economy. U.S. Department of Transportation, 2020. URL https: / / www. faa. gov/about/plans_reports/media/2020_ jan_economic_impact_report.pdf.

[6] Adejoke Adediran and. Foreign direct investment and sustainable development in nigerian aviation. Australasian Review of African Studies, 40(2):119-133, December 2019. doi: 10.22160/22035184/aras-2019-40-2/119-133. URL https : / / doi .org/10.22160/22035184/ aras-2019-40-2/119-133.
[7] Ladele M. What Are the Impacts of FDI Inflow on Eco nomic Growth of Emerging Economics? (A look at Brics). 2012.

[8] Mariasole Bannò and Renato Redondi. Air connectivity and foreign direct investments: economic effects of the introduction of new routes. European Transport Research Review, 6(4):355-363, April 2014. doi: 10.1007/s12544014-0136-2. URL https://doi.org/10.1007/ s12544-014-0136-2.

[9] Federal Aviation Administration. The Economic Impact of Civil Aviation on the U.S. Economy, Economic Impact of Civil Aviation by State. U.S. Department of Transportation, 2017. URL https://www. faa. gov/about/plans_reports/media/2017economic-impact-report.pdf.

[10] Federal Aviation Administration. The Economic Impact of Civil Aviation on the U.S. Economy. U.S. Department of Transportation, 2016. URL https://www.faa.gov/air_traffic/ publications/media/2016-economicimpact-report_FINAL.pdf.

[11] Federal Aviation Administration. The Economic Impact of Civil Aviation on the U.S. Economy, Economic Impact of Civil Aviation by State. U.S. Department of Transportation, 2015. URL https://www.faa.gov/ air_traffic/publications/media/2015economic-impact-report.pdf.

[12] Federal Aviation Administration. The Economic Impact of Civil Aviation on the U.S. Economy. U.S. Department of Transportation, 2014. URL https://www.faa.gov/air_traffic/ publications/media/2014-economicimpact-report.pdf.

[13] Air Transport Action Group. Aviation: Benefits Beyond Borders. 2018. URL https: //www.atag.org/component/attachments / attachments.html?id=707.

[14] Air Transport Action Group. Aviation: Benefits Beyond Borders. 2016. URL https: / / www . atag.org/component/attachments / attachments.html?id=607.

[15] Air Transport Action Group. Aviation: Benefits Beyond Borders. 2014. URL https: / / www.atag.org/component/attachments / attachments.html?id=710.

[16] Air Transport Action Group. Aviation: Benefits Beyond Borders. 2012. URL https: / / www. atag.org/component/attachments / attachments.html?id=840. 
[17] Air Transport Action Group. The economic and social benefits of air transport. 2005. URL https : //www.icao.int/meetings/wrdss2011/ documents/jointworkshop2005/atag_ socialbenefitsairtransport.pdf.

[18] Economic Benefits from Air Transport in the Czech Republic: The Czech Republic country report. Oxford Economics, 2011.

[19] Economic Benefits from Air Transport in the UK: UK country report. Oxford Economics, 2014. URL https://airlinesuk.org/wpcontent/uploads/2015/03/OxfordEconomics-2014.pdf.

[20] The Role of Business Aviation in the European Economy: UK country report. Oxford Economics, 2012. URL https://www.bbga.aero/wp-content/ uploads/2011/08/EBAA_Oxford_ReportFinal03-Digital1.pdf.

[21] The Economic Impact of Reduced Activity at Heathrow: Draft Report for the London Borough of Hounslow. Oxford Economics, 2020. URL https://www.hounslow.gov.uk/ downloads/file/2942/download_report.

[22] The Importance of Air Transport to the Czech Republic. International Air Transport Association, 2019. URL https://www.iata.org/en/iatarepository/publications/economicreports/czech-republic--value-ofaviation/.

[23] Aviation Satellite Account, Recommended Methodological Framework, Draft. International Civil Aviation Organization, 2019. URL https: //www. icao.int/ sustainability/Satellite/Documents / Draft $\% 20 \mathrm{Aviation} \% 20$ Satellite\% 20 Account $\% 20$ Methodological\% 20Framework. pdf.

[24] United Nations, European Commission, International Monetary Fund, Organisation for Economic Co-operation and Development, and World Bank, editors. System of national accounts 2008. United Nations, New York, 2009. ISBN 9789211615227. OCLC: ocn526091359.

[25] United Nations, editor. International Standard industrial classification of all economic activities (ISIC). Number no. 4 , rev. 4 in Statistical papers. Series M. United Nations, New York, rev. 4 edition, 2008. ISBN 9789211615180. OCLC: ocn277738900.

[26] Central Product Classification (CPC). Department of Economic and Social Affairs, Statistics Division: United Nations, 2015.
[27] NACE Rev. 2, Statistical classification of economic activities in the European Community. Eurostat, 2008. URL https://ec.europa.eu/eurostat/ documents/3859598/5902521/KS-RA-07015-EN.PDF.

[28] Český statistický úřad and Odbor obecné metodiky. Klasifikace ekonomických činností (CZ-NACE). Český statistický úřad, Praha, 2008. ISBN 9788025016602. OCLC: 228782862.

[29] Klasifikace ekonomických činností (CZ-NACE). Český statistický úřad, 2007. URL https: //www.czso.cz/csu/czso/klasifikace_ ekonomickych_cinnosti_cz_nace. 